\title{
Estratégias organizacionais de sustentabilidade e o contexto institucional: implicações a partir do discurso da mídia de negócios
}

\section{Organizational sustainability strategies and the institutional context: implications from business media discourse}

\author{
VANESSA MAES* \\ EDSON RONALDO GUARIDO FILHO** \\ MAYLA CRISTINA COSTA***
}

\section{RESUMO}

O presente trabalho tem como objetivo compreender a relação entre a ressonância social e a legitimidade de estratégias organizacionais de sustentabilidade manifestadas no discurso da mídia de negócios. A pesquisa foi realizada com base em textos produzidos na mídia de negócios por meio da Revista Exame, entre 1992 e 2013. A partir de análise exploratória, foram criadas proposições e foram encontrados quatro frames que traduzem as estratégias de sustentabilidade: i) responsabilidade social das organizações; ii) resultante do impacto ao meio ambiente e de pressões ambientais; iii) estratégias de marketing; iv) práticas de ecoeficiência. Como resultado da pesquisa, argumenta-se que os discursos da mídia de negócios participam do processo de construção das bases institucionais das estratégias organizacionais de sustentabilidade, promovendo a difusão de ideias consideradas socialmente aceitas e auferindo legitimidade às ações organizacionais.

Palavras-chave: Estratégias de sustentabilidade. Mídia de negócios. Legitimidade organizacional.

* Mestre em Administração pela Universidade Positivo.

** Universidade Positivo. Universidade Federal do Paraná. Professor do Programa de Mestrado e Doutorado em Administração da Universidade Positivo. edson.guarido@gmail.com .

*** Universidade Federal do Paraná. Professora do Programa de Mestrado e Doutorado em Contabilidade da Universidade Federal do Paraná. mayla.c.costa@gmail.com . 


\section{Abstract}

The purpose of this paper is to understand the relationship between social resonance and legitimacy of organizational sustainability strategies expressed in the business media discourse. The research was conducted based on documentary material produced by an specific business media represented by texts published by Exame Magazine, between 1992 and 2013. Based on an exploratory analysis, we draw propositions about the organizational reality and four frames were found that express sustainability strategies: i) corporate social responsibility; ii) the resulting effect from impact on the environment and environmental pressures; iii) marketing strategies; iv) eco-efficiency practices. As conclusion, we argued that business media discourses help to build the institutional foundations of organizational sustainability strategies, promoting the diffusion of ideas considered socially acceptable and conferring legitimacy to organizational practices. Key-words: Sustainability strategies. Business media. Organizational legitimacy.

\section{INTRODUÇÃo}

A abordagem do institucionalismo organizacional considera que os comportamentos individuais e organizacionais estão sempre inseridos em uma realidade social (SCOTT, 2008). Nessa perspectiva, uma vez que determinadas ações são tidas como legítimas pela sociedade, os comportamentos são reforçados. Da mesma forma, os comportamentos tendem a ser refutados à medida que não são aceitos no contexto social. Nesse processo contínuo e reflexivo de reforço e refutação, os padrões vão sendo socialmente construídos originando as instituições (BERGER \& LUCKMANN, 1998).

Por esse motivo, a legitimidade (aprovação social) é considerada pela abordagem o fator que dá credibilidade às organizações (SCOTT, 2008). Nesse sentido, uma vez que determinadas estratégias são entendidas como ações que aumentam a legitimidade, a utilização de tais estratégias dissemina-se no ambiente institucionalizado de maneira a tornar as práticas organizacionais similares. O processo de disseminação dessas estratégias é considerado neste artigo como ocasionado pela emissão de discursos, advindos das pressões do contexto institucional, uma vez que as reflexões dos anseios 
da sociedade são os fatores legitimadores da ação organizacional (FAIRCLOUGH, 2001).

A mídia, nesse sentido, é responsável por transmitir discursos que refletem o contexto institucional, interferindo no processo de institucionalização (ADAMAGLU DE OLIVEIRA, GODRI, COSTA \& GUARIDO FILHO, 2016), e exercem influência como elemento de ressonância social, que legitima instituições que permeiam determinado contexto (RICHARDSON, 2007). Com essa compreensão, é possível afirmar que as estratégias organizacionais de sustentabilidade, cada vez mais presentes, vão sendo reforçadas à medida que movimentos em torno da sustentabilidade crescem. Da mesma forma, discursos de sustentabilidade, sejam no âmbito organizacional ou no midiático, contribuem para a legitimidade dos comportamentos uma vez que mais discursos e estratégias em torno da sustentabilidade estão ocorrendo (COELHO \& GODOI, 2010).

Nesse sentido, observa-se que as pesquisas que utilizam discurso de maneira teorética na vertente institucional visam explicar que os processos institucionais são fundamentais para a construção social (ADAMAGLU DE OLIVEIRA et al., 2016), no entanto, no que concerne à ampliação da compreensão acerca das práticas organizacionais, percebe-se ainda pouca expressão em relação ao papel social da mídia como um espaço de ressonância social (LEVERO, 2014). Ademais, o presente trabalho justifica-se também porque os frames, aqui utilizados, podem tanto abarcar uma contribuição metodológica quanto prática na medida em que são úteis para a compreensão de quaisquer processos de institucionalização. Assim sendo, o objetivo deste artigo centra-se em compreender a relação entre a ressonância social e a legitimidade de estratégias organizacionais de sustentabilidade manifestadas no discurso da mídia de negócios, representado pela Revista Exame, no período de 1992 a 2013.

Este artigo é estruturado em cinco seções: esta introdução; a segunda seção, apresentando o referencial teórico com a representação das questões relativas ao conceito de instituições e dos processos de institucionalização, incluindo contextos institucionais, atores e a construção da linguagem na disseminação dos discursos. A seção 3, em que os procedimentos metodológicos adotados são descritos, bem como, a explanação da sintetização de ideias em agrupamentos chamados de frames; a seção 4, que explora os dados encontrados 
sintetizando os discursos midiáticos em quatro frames, por fim, a seção 5, que exibe as conclusões e discussões que permeiam o discurso midiático como constitutiva da legitimidade das estratégias organizacionais, assim como sugestões para futuros trabalhos.

\section{INSTITUCIONALISMO ORGANIZACIONAL}

A institucionalização como uma construção de significados é um processo que trata da linguagem como condutora das práticas institucionalizadas (BERGER \& LUCKMANN, 1998), o que se dá mediante a interação social que ocorre entre os atores. Assim, os padrões institucionalizados são parâmetros para a legitimidade pela sociedade (FONSECA \& MACHADO-DA-SILVA, 2002). As instituições, por assim dizer, são construídas socialmente dentro de um contexto. Isso porque o ambiente não apenas é uma arena onde as interações ocorrem, mas torna-se uma referência para a ação organizacional. Nesse sentido, a definição tradicional, colocada por Scott (2008), considera instituição como o sistema compartilhado de ideias que permeiam o ambiente institucional (LAWRENCE \& SUDDABY, 2006).

Nesse sentido, Suchman (1995) destaca que o conceito de legitimidade pode se apresentar de maneira reflexiva. A incorporação de mitos racionais pode ser um fator que provê legitimidade (MEYER \& ROWAN, 1977; SAHLIN \& WEDLIN, 2008). As organizações tornam-se isomórficas para assegurar a legitimidade, que provê benefícios, mesmo sendo as práticas institucionalizadas contrárias à eficiência (GREENWOOD, OLIVER, SAHLIN \& SUDDABY, 2008). Assim, "quanto mais organizações se conformarem com estes mitos, tanto mais eles se tornarão mais profundamente institucionalizados" (BOXENBAUM \& JONSSON, 2008, p. 78).

Além disso, é possível contestar o caráter determinístico que os contextos institucionalizados carregam em relação à ação organizacional. Ou seja, a institucionalização é um processo sensível aos significados presentes nos contextos que moldam os padrões sociais (ZILBER, 2008). Os elementos institucionalizados, portanto, são difundidos dentro de um contexto a partir de componentes portadores (SCOTT, 2003). Para Scott (2008), os portadores dos pilares institucionais são: sistemas simbólicos, sistemas relacionais, rotinas e artefatos. Scott (2008) define como sistemas simbólicos o conjunto 
de elementos que representam as normas e padrões. Os sistemas relacionais são, para ele, referentes às redes de interações entre os elementos do sistema. A rotina, por sua vez, reflete os comportamentos habitualizados. Os artefatos, por fim, estão relacionados à capacidade humana de criar objetos que auxiliam suas atividades (tecnologias), incorporando técnicas e elementos simbólicos.

Como "a luta pelo sentido envolvido na institucionalização é especialmente evidente nos estudos que seguem os esforços discursivos de competição institucional de atores" (ZILBER, 2008, p. 158), é possível compreender que a construção social dos significados institucionalizados transcorre do conceito da linguagem, uma vez que a linguagem medeia as interações e a concepção de significados atribuídos. A consecução de sentido, no entanto, é dada pela interpretação dos aspectos produzidos no texto (FAIRCLOUGH, 2001). Por meio do uso da linguística discursiva, portanto, os atores, presentes no contexto institucional, contribuem para a manutenção ou ruptura das instituições (FAIRCLOUGH, 2001). Para o autor, amparados na linguagem que intermedeia a condução das instituições, os atores interferem na realidade em que estão inseridos.

Não se pode deixar de abordar, nesse sentido, a importância de atores na construção dos contextos institucionais. Para Scott (2003), os atores podem estar amparados em construções simbólicas e relacionais, apesar de se tornarem influentes à medida que compilam informações e transformam ações. Assim, é possível apontar que a forma como as instituições mudam dentro do tempo e espaço está associada à abordagem dada pelos atores nesse processo.

\section{Discursos E Mídia Na CONSTRUÇão SOCIAL}

Uma vez que os atores têm capacidade de interferência no meio social ocasionando alterações nas instituições vigentes, as conexões estabelecidas dentro do sistema têm relação com os discursos que circulam entre os atores (LEVERO, 2014). O meio social, nesse sentido, é construído a partir de interações mediadas pelos discursos (GUIDDENS, 1984).

Os discursos, propriamente ditos, são representações simbólicas por meio de textos, imagens ou sons, imbuídos de semânticas, produzidos e consumidos pela sociedade (FAIRCLOUGH, 2001). A análise do discurso, por assim dizer, é uma ferramenta metodológica 
capaz de extrair a discussão entre os significados dos discursos e seus contextos. Isso porque, segundo Fairclough (2001), envolve a ideologia por trás das mensagens em um processo de interdiscursividade construído com o ambiente social.

A definição de discurso, nesse sentido, é complexa, no entanto, é muito explorada na análise social (FAIRCLOUGH, 2001). O processo de construção de crenças compartilhadas é realizado pela ação dos atores envolvidos no contexto que constroem socialmente não apenas a ideologia, mas os discursos dominantes (GUIDDENS, 1984). Nesse sentido, para Fairclough (2001), discurso e estrutura social formam uma dialética à medida que se influenciam de maneira reflexiva. Da mesma forma, Phillips e Malhotra (2008) colocam a manifestação discursiva como parte da significação da construção social. $\mathrm{Ou}$ seja, o processo de institucionalização passa por uma dinâmica de imitação da ação que, por meio da produção de textos, constroem discursos que, por sua vez, institucionalizam as ações (PHILLIPS, LAWRENCE \& HARDY, 2004).

Ou seja, os fluxos de informação reforçam a construção de significados sociais. Para Menezes e Guedes (2011, p. 101), “a mídia e o discurso midiático transmitem informações e conteúdo simbólicos e terminam por influenciar as relações dos indivíduos e das sociedades". O processo contínuo de construção de imagens mediante representações sociais pelos meios de comunicação, como explica Oliveira (2012), ora reproduzem, ora produzem a realidade da sociedade. Segundo o autor, os indivíduos tomam a mídia como referência para se localizarem no mundo e determinarem sua forma de agir, isso porque os meios de comunicação passam credibilidade e legitimidade à sociedade. A partir da interpretação dada a cada discurso, ações são geradas entre os atores sociais no sentido de promover uma mudança ou manter a estabilidade das instituições existentes.

Tal mudança, conforme a Figura 1, passa por um processo contínuo de interação entre ações dos atores, a produção dos artefatos textuais que geram os discursos que, por sua vez, dão origem às instituições que motivam novas ações (PHILLIPS et al., 2004). Para os autores, esse processo contínuo de construção das instituições molda as ações sociais de forma recíproca e interativa conforme ações, discursos e instituições são construídos socialmente. 
Figura 1 - Um modelo discursivo da institucionalização

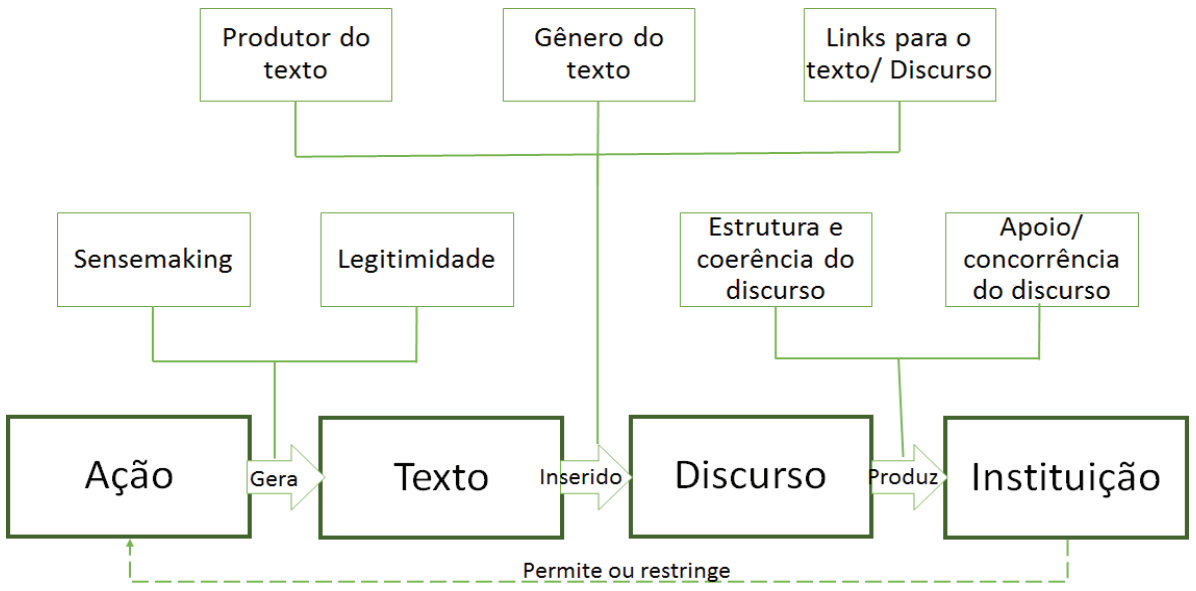

Fonte: Adaptado de Phillips et al. (2004, p. 641).

A mídia tem o poder de interferir nas percepções da sociedade, influenciando suas ideologias e moldando a realidade social (CHIGONA \& MOOKETZI, 2011). A escolha do processo linguístico que será explorado, portanto, depende da significância ideológica que o emissor pretende dar (FAIRCLOUGH, 2001). Conforme já mencionado, para Fairclough (2001), as práticas discursivas refletem as ideologias de construção da realidade enquanto dão sentido às práticas sociais contribuindo para a sua produção, manutenção ou transformação. Na realidade, a mídia tem o poder de interferir nas ações organizacionais, bem como, nas relações interorganizacionais por meio da cobertura dada a cada discurso (CAVAZOS \& RUTHERFORD, 2011).

Dessa maneira, a produção e a disseminação dos textos por meio de símbolos compartilhados geram discursos com potencial para modificar ou criar novas instituições (HARDY, 2011). Isso decorre da assimetria existente nos diferentes contextos, fazendo que os elementos sociais desenvolvam as regras de interação e por conseguinte as mensagens institucionais originadas em tal integração (LAMMERS, 2011), o que faz as ideias serem disseminadas pelo meio social. 


\section{ESTRATÉGIAS ORGANIZACIONAIS DE SUSTENTABILIDADE, Mí- DIA E DISCURSO}

Com base na consideração de que as ideias estão disseminadas no contexto institucional por meio dos discursos proferidos pela mídia (PHILLIPS et al., 2004), busca-se, então, captar a construção dos conceitos de estratégias organizacionais de sustentabilidade que estão presentes nos meios de comunicação de massa, visto que tais estratégias vêm sendo proliferadas. Compreende-se aqui que as estratégias são socialmente construídas e quando estão em maior conformidade com o ambiente tendem a ser consideradas legítimas no contexto institucional (DEEPHOUSE, 1999).

A legitimidade das ações estratégicas, nesse sentido, aparece nos discursos, uma vez que estes legitimam as ações e as constroem subjetivamente (GOLSORKHI, ROULEAU, SEIDL \& VAARA, 2010). A partir da construção social, tais estratégias são tidas como corretas, o que origina discursos em torno das ações de sustentabilidade (CARRIERI, LEITE DA SILVA \& PIMENTEL, 2009).

Enquanto a primeira Conferência Mundial de Proteção ao Meio Ambiente, realizada em Estocolmo, em 1972, reuniu cerca de mil pessoas, representantes de 113 países e de 400 entidades não governamentais, a segunda Conferência ocorreu no Rio de Janeiro, em 1992, e reuniu em torno de 22 mil pessoas nos eventos oficiais (CARVALHO \& KASSAI, 2013). De acordo com os autores, a terceira e última Conferência, a RIO+20, realizada em 2012, também no Rio de Janeiro, reuniu 110 mil pessoas nos eventos oficiais e mais de 1 milhão de pessoas nos eventos paralelos.

Para Coelho e Godoi (2010), a mídia ampliou os discursos de sustentabilidade à medida que dá destaque às questões ambientais. Isso porque as práticas discursivas contribuem tanto para reproduzir a sociedade como para transformá-la, conforme já mencionado (FAIRCLOUGH, 2001). Por um lado, os discursos midiáticos de responsabilidade socioambiental refletem os padrões de comportamento sociais realizados pelas organizações, por outro interferem na realidade reforçando e modificando tais padrões (ZILBER, 2008; HARDY, 2011).

A crescente preocupação da sociedade com a sustentabilidade está ligada aos impactos sociais e ambientais que as organizações provocam (ALIGLERI, ALIGLERI \& KRUGLIANSKAS, 2009). Nas 
últimas décadas, no entanto, tal preocupação vem se materializando em estratégias organizacionais que consideram o aspecto da sustentabilidade cada vez mais legitimado pelo contexto. Assim, o ambiente organizacional aponta uma necessidade de adequação das estratégias organizacionais às questões de sustentabilidade, uma vez que a competitividade passa a ser considerada "na perspectiva de estratégias de gestão e postura socialmente correta, ambientalmente sustentável e economicamente viável" (ALIGLERI et al., 2009, p. 3).

Tais discursos estão em consonância com o discurso do mercado, uma vez que ocorre a intervenção das organizações para a aplicação dos discursos de sustentabilidade que advêm de pressões sociais (GUIMARÃES \& FONTOURA, 2012). Tais pressões originam-se tanto na esfera pública como na privada, envolvendo consumidores, fornecedores, funcionários entre outros (BARBIERI, 2008). Para Carrieri et al. (2009), no entanto, as pressões se alteram de acordo com os contextos sociais.

Sob essa ótica, torna-se possível analisar as estratégias organizacionais de sustentabilidade como ações sociais impregnadas de legitimadas. Tais ações, por sua vez, geram discursos de sustentabilidade coerentes com o contexto em estrutura e conteúdo. Tal coerência é o fator que origina a legitimidade das ações, uma vez que os discursos de sustentabilidade criam instituições que, por sua vez, permitem ou restringem as estratégias de sustentabilidade das organizações (PHILLIPS et al., 2004).

\section{Procedimentos metodológicos}

Para esclarecer de que modo a pesquisa foi conduzida, são abordados a forma como foi realizada e os procedimentos de coleta e análise. Nesse sentido, é definida a configuração de seleção da revista analisada, bem como o detalhamento das etapas de coleta e análise dos dados.

Como o estudo contempla a análise de textos que envolvem visões de mundo e valores que se refletem nos fenômenos humanos (RICHARDSON, 2007), foi realizada uma pesquisa em caráter qualitativo por meio de uma análise de discurso. A unidade de análise são os textos emitidos pelos meios de comunicação de massa em torno das estratégias organizacionais de sustentabilidade. Os discursos emergentes no contexto foram divididos em frames para uma melhor compreensão. 
Foi utilizado um corte temporal longitudinal, no período de 1992 a 2013. A escolha do período decorre do fato de 1992 ser o ano em que ocorreu o evento conhecido como a ECO-92, a partir do qual inicia-se uma onda mais consistente em torno de discursos de sustentabilidade (CARVALHO \& KASSAI, 2013). Considera-se que a partir desse período é possível perceber a disseminação de discursos e estratégias em torno da sustentabilidade (ZILBER, 2008).

Foi feita a análise de conteúdo aos moldes de Rivenburgh (2011), no qual identificam-se frames (quadros) presentes nos discursos, realizando-se, então, uma síntese dos frames encontrados. Os frames, dessa forma, estão baseados na identificação de causas, soluções, implicações, avaliação e prospecto.

Assim, para a realização da pesquisa, foram estabelecidas cinco etapas: a) Seleção dos textos a respeito das estratégias organizacionais de sustentabilidade; b) Análise documental: caracterização do corpo do texto; c) Análise de conteúdo: Identificação indutiva dos frames; d) Análise qualitativa de conteúdo: Síntese dos frames e enquadramento; e) Análise exploratória: Interpretação dos dados.

Como a mídia virtual está cada vez mais difundida na sociedade, a presente pesquisa utilizou os artigos veiculados em websites como balizador dos discursos emitidos na sociedade. Destaca-se, portanto, que todos os textos analisados foram exclusivamente retirados de sítio virtual da própria revista estudada disponível amplamente em website da internet.

Foram utilizados a princípio, para a análise de discurso, textos jornalísticos originados em revistas de negócios que possuem maior circulação, no Brasil, segundo os dados da Associação Nacional de Editores de Revistas (ANER) e do Instituto Verificador de Circulação (IVC). Além disso, procurou-se realizar uma seleção de casos instrumentais, ou seja, não somente o veículo mais lido, mas de acordo com a abrangência nacional, tendo seu conteúdo publicado no meio virtual e que possuísse circulação a pelo menos dez anos para que a análise temporal fosse significativa. Dentro desses veículos, foram avaliados os textos produzidos entre 1992 e 2013. Na referida listagem, escolheu-se a revista de negócio com maior circulação nesse período, ou seja, a Revista Exame.

Aos moldes de Riaz, Buchanan e Bapuji (2011), foram selecionados textos a partir de buscas virtuais por palavras-chave. A partir de então, foram extraídos todos os textos que tratavam de estratégias 
organizacionais de sustentabilidade. Optou-se em utilizar palavras-chave que remetam ao assunto a ser estudado: "sustentabilidade"; "estratégias"; "responsabilidade" "social" e "ambiental". Antes do tratamento dos dados, no entanto, os textos passaram por uma primeira triagem visual de adequação ao objetivo proposto.

Para este estudo, optou-se em utilizar a análise do discurso, uma vez que a linguística foi analisada imersa no contexto cultural da sociedade. Além disso, esta análise pressupõe que os discursos são práticas sociais que interferem no ambiente, sendo parte constitutiva das interações sociais (FAIRCLOUGH, 2001). A separação por datas, utilizando o software NVivo, foi a primeira fase da análise.

Os textos escolhidos para a análise foram, então, inseridos no software NVivo, onde recebem as leituras que conduziram às fases da análise. Ou seja, da mesma forma como Riaz, Buchanan e Bapuji (2011), os textos sofreram uma análise documental onde foram tabulados a partir de dados gerais como: fonte do texto, data, título, principais temas abordados, atores envolvidos e principal discurso. Esse modelo metodológico foi construído a partir de modelos de análise utilizados em estudos similares (DIRIKX \& GELDERS, 2010; RIAZ, BUCHANAN \& BAPUJI, 2011; RIVENBURGH, 2011).

Somente após a tabulação, foi iniciada a análise de conteúdo para originar os principais frames em torno das estratégias organizacionais de sustentabilidade. A partir de uma análise de conteúdo, as palavras similares citadas nos textos descritos na tabela foram reunidas de acordo com a proximidade cronológica. Desse modo, encontraram-se os frames contidos em cada período. Para a descrição dos frames foi, então, realizada uma nova análise de conteúdo dentro dos nós contidos nas categorias: causas, solução, implicação, avaliação e prospecto.

Aos moldes de Dirikx e Gelders (2010) e Rivenburgh (2011) que realizaram uma análise quantitativa dos jornais que apresentavam ideologias distintas a partir da resposta de algumas perguntas buscando-se um enquadramento de conteúdo, pretendia-se realizar uma análise a fim de encaixar os textos em frames. De acordo com Rivenburgh (2011), são identificados os principais focos, gerando-se frames gerais que representam a realidade, nesse sentido foram percebidos os focos por meio de uma análise de conteúdo qualitativa mais aprofundada. Em seguida, foram feitas análises em torno da 
busca pela emergência de frames que elucidassem as ideologias intrínsecas aos discursos presentes nos textos com a utilização do software NVivo.

Com os principais frames definidos, partiu-se para o enquadramento dos dados. Ou seja, os frames encontrados foram classificados de acordo com a unidade originária do texto. De posse de tais informações, foi possível traçar um quadro evolutivo dos frames no decorrer de seu desenvolvimento, separados por quatro momentos principais. Uma vez que os textos estavam devidamente codificados e os frames separados, foi possível realizar uma análise de conteúdo dentro de cada grupo em que estavam inseridos. Tal análise procurou encontrar os padrões de palavras, expressões e assuntos abordados dentro de cada frame.

Por fim, a análise do discurso foi empreendida para a percepção ideológica ao qual cada discurso pertence. A análise final, no entanto, trata-se da interpretação a partir dos enquadramentos originados nos softwares. Assim, a interpretação de cada caso e frame estudado originou a análise dos discursos acerca das estratégias organizacionais de sustentabilidade.

\section{APRESENTAÇÃo E ANÁlise doS DADOS}

Nesta seção, realiza-se a apresentação e a interpretação dos dados encontrados. Para tanto, inicia-se com a descrição da análise documental que embasou a contextualização ideológica dos discursos analisados. Em um segundo momento, foram separados os frames que compõem cada discurso, considerando que a mídia opera como agente amplificador dos discursos a mesma medida que se torna uma justificativa de legitimidade (FAIRLOUGH, 2001; GIDDENS, 2004; HARDY, 2011). Compreendendo-se, então, que a composição de cada discurso foi composta pela observação analítica que emergiu da leitura dos 429 textos retirados da mídia (PHILLIPS et al., 2004).

Primeiramente, é interessante observar o número de textos que foram publicados em cada momento histórico. Tal processo demonstra que há um aumento gradativo no decorrer do tempo, mas com o tempo as discussões diminuem. Essa situação pode nos levar a induzir que conforme os conceitos vão se concretizando, a ressonância social dada para o tema torna-se mais legítima no meio social, não sendo necessárias certas discussões. 
Figura 2 - Número de Textos por AnoFonte:

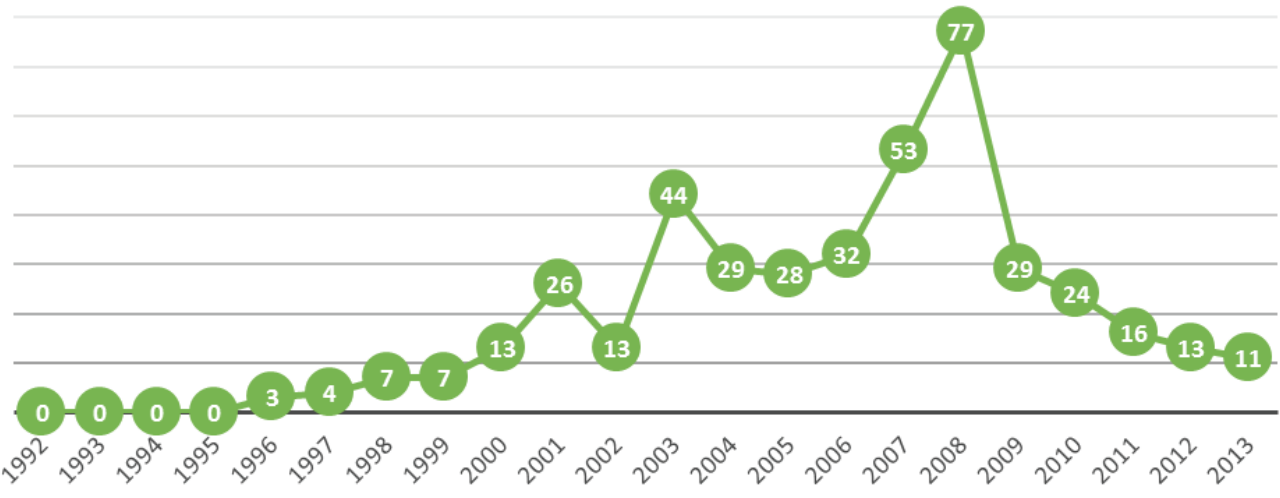

Elaborado pelos autores com base nos dados da pesquisa.

Observou-se também que o tema sustentabilidade dentro da área de negócios só começou a ganhar corpo após os anos 2000, tendo um ápice das discussões, principalmente em 2008, o que define as principais diretrizes de ações tidas como certas para o meio organizacional. A partir do modelo de Phillips et al. (2004), é possível inferir que a ação que gera o texto inserido nos discursos depende do sensemaking e legitimidade no processo de institucionalização, ou seja, a partir do sensemaking e da própria legitimidade acerca do ser sustentável que as empresas passam cada vez mais a adotar estratégias e a mídia de negócio a reproduzi-las em processo recursivo.

Em relação ao formato disponibilizado ao leitor, a questão envolve a forma como o texto será lido e até mesmo interpretado, isso porque interfere diretamente na abordagem e grau de convencimento utilizado. Nesse quesito, observou-se que $88 \%$ dos textos publicados na mídia de negócios a respeito de estratégias de sustentabilidade estão enquadrados no formato reportagem.

Assim sendo, é interessante destacar que a maioria dos textos analisados é de reportagens curtas, em torno de duas páginas. Os textos ainda têm preferência pela abordagem mais ampla, não evidenciando muitas organizações. Quando trata de alguma organização, normalmente se refere à indústria de base ou bens de consumo. Tais dados representam a abordagem da mídia de negócios centrada na explicação dos conceitos e estratégias de sustentabilidade que 
podem ser aplicados nas organizações, apresentando as possíveis soluções e implicações para cada estratégia.

Com o objetivo de compreender as percepções gerais de conteúdo utilizadas pelo texto de uma forma geral, foram questionadas algumas ferramentas de enfoque na questão como a moral representada, os sentimentos envolvidos, consequências apresentadas ou o grau de prescrição que o texto empregava. A análise destaca que apenas $23 \%$ dos textos mostram alguma lição de moral de forma evidente. A abordagem utilizada nos textos analisados está focada na transmissão de informações objetivas que demonstrem e justifiquem as estratégias de sustentabilidade. Os textos observados tendem, ainda, a tratar o assunto de maneira mais objetiva, colocando informações das possíveis estratégias de sustentabilidade sem extravasar para o caráter prescritivo, o que não demonstra uma abordagem tão agressiva.

Os níveis de tratamento das pessoas e organizações estão ligados ao grau de subjetividade apresentado. Apesar disso, mais de $30 \%$ evidenciam questões que podem gerar algum sentimento por parte do leitor. As informações ainda esclarecem que poucos textos representam dois ou mais lados da questão, mas metade deles mostra de que forma os indivíduos ou grupos estão sendo afetados pelo problema/solução.

Notou-se, ademais, uma evidência em relação ao encorajamento que o texto traz para a aplicação de estratégias de sustentabilidade nas organizações. Isso porque há a formação de um conceito compartilhado de que ações de sustentabilidade são bem vistas pela sociedade (PHILLIPS et al., 2004). Essa questão, no entanto, representa o caráter descritivo da abordagem persuasiva apresentada pelos textos analisados.

A compreensão dos discursos de estratégias organizacionais de sustentabilidade se dá por meio da identificação de frames (DIRIKX \& GELDERS, 2010). Tais frames foram encontrados por meio de uma busca por palavras-chave, identificando proximidades semânticas. Uma vez que a tabela estava construída, foi observada a quantidade de palavras estabelecendo assuntos similares cronologicamente próximos, originando a separação dos frames.

As buscas tiveram a intenção de reunir os termos similares a fim de caracterizar os frames por meio de causas, soluções, implicações, 
avaliação e prospecto. Os tópicos foram reunidos de acordo com a convergência a um tema mais amplo, o que deu maior amplitude temporal aos discursos encontrados. Como resultado, foram identificados quatro principais frames, conforme descritos no Quadro 1

\section{Quadro 1 - Conteúdo dos Frames Encontrados}

\begin{tabular}{|c|c|c|c|c|c|}
\hline & Causas & Soluções & Implicações & Avaliação & Prospecto \\
\hline 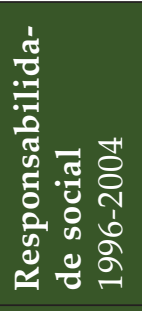 & $\begin{array}{l}\text { Social } \\
\text { Comunidade }\end{array}$ & $\begin{array}{l}\text { Voluntariado } \\
\text { Responsabili- } \\
\text { dade } \\
\text { Comunidade } \\
\text { Inclusão } \\
\text { Funcionários } \\
\text { Ética } \\
\end{array}$ & $\begin{array}{l}\text { Lucro } \\
\text { Imagem } \\
\text { Funcionários }\end{array}$ & $\begin{array}{l}\text { Modismo } \\
\text { Mensurar }\end{array}$ & $\begin{array}{l}\text { Expansão da } \\
\text { estratégia }\end{array}$ \\
\hline 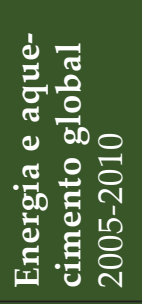 & $\begin{array}{l}\text { Energia } \\
\text { Renovável } \\
\text { Aquecimento } \\
\text { global } \\
\text { Carbono }\end{array}$ & $\begin{array}{l}\text { Energia } \\
\text { Alternativa } \\
\text { Etanol } \\
\text { Diminuição de } \\
\text { carbono e cré- } \\
\text { ditos }\end{array}$ & $\begin{array}{l}\text { Energia } \\
\text { Redução de } \\
\text { custos } \\
\text { Desenv. sus- } \\
\text { tentável } \\
\text { Redução da } \\
\text { emissão } \\
\end{array}$ & $\begin{array}{l}\text { Energia } \\
\text { Sustentável } \\
\text { (postura) }\end{array}$ & $\begin{array}{l}\text { Energia } \\
\text { Desenvolv. } \\
\text { tecnologia }\end{array}$ \\
\hline 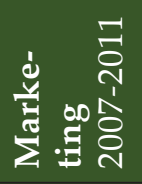 & $\begin{array}{l}\text { Marketing } \\
\text { Imagem } \\
\text { Modismo }\end{array}$ & $\begin{array}{l}\text { Marketing } \\
\text { Produto verde } \\
\text { Certificações }\end{array}$ & $\begin{array}{l}\text { Imagem } \\
\text { Vantagem } \\
\text { competitiva }\end{array}$ & $\begin{array}{l}\text { Muito tra- } \\
\text { balho a ser } \\
\text { feito }\end{array}$ & $\begin{array}{l}\text { Mercado } \\
\text { promissor } \\
\text { Reduzir os } \\
\text { problemas }\end{array}$ \\
\hline 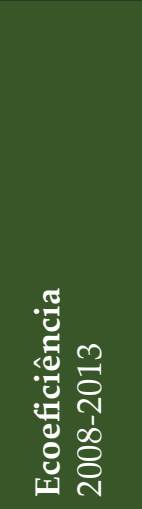 & $\begin{array}{l}\text { Resíduos } \\
\text { Água } \\
\text { Recursos não } \\
\text { renováveis }\end{array}$ & $\begin{array}{l}\text { Eficiência } \\
\text { Redução de des- } \\
\text { perdício } \\
\text { Reaproveita- } \\
\text { mento resíduos } \\
\text { Tecnologia } \\
\text { Uso eficiente da } \\
\text { água } \\
\text { Economia de } \\
\text { recursos } \\
\text { Incentivo ao } \\
\text { fornecedor }\end{array}$ & $\begin{array}{l}\text { Redução de } \\
\text { custos } \\
\text { Melhor apro- } \\
\text { veit. dos } \\
\text { recursos }\end{array}$ & Eficiência & $\begin{array}{l}\text { Desenv. de } \\
\text { tecnologias } \\
\text { Qualidade } \\
\text { de vida } \\
\text { Reduzir } \\
\text { consumo de } \\
\text { água }\end{array}$ \\
\hline
\end{tabular}

Fonte: elaborado pelos autores com base nos dados da pesquisa. 
A partir da análise descrita, foi possível perceber que o primeiro discurso identificado se refere a questões ligadas à responsabilidade social. O período entre 1996 até 2004, correspondente ao início das discussões a respeito do assunto, nem mesmo utiliza o termo "sustentabilidade". Isso porque, os conceitos ainda estavam sendo formados pelos discursos, ainda não eram legitimados (PHILLIPS et al., 2004). No entanto, as organizações passam a ser vistas como corresponsáveis pelo impacto que causam ao meio ambiente e à sociedade. A preocupação social, especialmente para com pessoas que circundam a organização, emerge primeiramente, já que as organizações possuem dependência das pessoas envolvidas, seus stakeholders (CARVALHO \& KASSAI, 2013).

Tais estratégias são avaliadas como uma espécie de modismo que surge no meio empresarial, gerando uma ação multiplicadora, em concordância com estudos da teoria institucional (LAWRENCE \& SUDDABY, 2006). Os textos destacam ainda a falta de mensuração tanto das ações como dos resultados e das possíveis implicações, tanto para a organização como para a sociedade. Além disso, 65\% dos textos destacam a expectativa de expansão das estratégias de sustentabilidade como a projeção para o futuro.

O segundo discurso, observado a partir dos textos analisados, se refere ao componente ambiental. Nesse sentido, tornam-se mais evidentes as discussões a respeito das relações de responsabilidade das organizações no impacto que causam ao meio ambiente. Assim, percebe-se que, no período de 2005 a 2010, se destacam os problemas causadores do aquecimento global que começam a preocupar muito a sociedade, bem como, alternativas de energia que possam ser mais eficientes e causar menos impacto, especialmente sobre a poluição e aquecimento global.

Dessa forma, percebe-se, ademais, que as estratégias de sustentabilidade são vistas como uma postura organizacional capaz de orientar as ações da organização de forma holística e integrada no sistema de gestão. Há incentivos ao desenvolvimento de tecnologias, especialmente para a procura de alternativas de energia renovável, capazes de tornar as organizações não apenas mais lucrativas, mas mantenedoras do desenvolvimento sustentável e por conseguinte melhor vistas pela sociedade.

É possível averiguar ainda um terceiro grupo de textos que formam um discurso em torno das questões ligadas à imagem que 
o uso de estratégias de sustentabilidade é capaz de trazer às organizações. Especialmente, entre os anos 2007 e 2011, há um realce para o uso da sustentabilidade no sentido de se obter uma vantagem competitiva por meio da legitimidade que tais estratégias vão ganhando ao longo do tempo. Assim sendo, a sustentabilidade começa a ser tratada pelos textos como uma estratégia essencialmente mercadológica.

Nesse sentido, ações de sustentabilidade também são vistas como um mercado promissor a ser explorado pelas organizações. Isso pode ser percebido pela própria avaliação feita pelos textos em que $12 \%$ acreditam que ainda há muito trabalho a ser feito para que se atinja o desenvolvimento sustentável. Espera-se, também que essas ações reduzam o impacto causado tanto ao meio ambiente quanto ao âmbito social.

A ecoeficiência é um conceito que surge da necessidade de aliar o ganho obtido com estratégias de sustentabilidade organizacional. Ou seja, a partir principalmente de 2008, a sustentabilidade passa a ser vista como uma forma de se obter maior eficiência nos processos organizacionais. $\mathrm{O}$ aumento da eficiência decorrente da sustentabilidade é considerado atingir as organizações de uma forma holística, inclusive integrando com estratégias de seus stakeholders, especialmente na pressão em relação aos fornecedores e outros componentes da cadeia produtiva.

Como pode ser observado mediante definição dos frames obtidos nos textos, os discursos que emergem se interpõem, essencialmente após 2005 em que o tema torna-se mais discutido. Essa relação evidencia o caráter amplificador que a mídia possui em relação aos discursos sociais. Ademais, quanto mais textos são publicados pela mídia evidenciando o tema, tanto mais as estratégias de sustentabilidade ganham legitimidade no contexto em que estão inseridas, reforçando as discussões da sociedade e ampliando a profundidade do assunto (PHILLIPS et al., 2004). As discussões mais recentes, ainda preocupadas com o ganho econômico, percebem a sustentabilidade como uma forma de se obter eficiência.

Observa-se que o discurso da "Responsabilidade social", embora mais extenso em termos temporais, pertence a um período com um volume menor. Isso porque, esse período representa um esboço das discussões sociais a respeito do assunto. À medida que as discussões 
se intensificam, aumenta o grau de complexidade da abordagem, bem como a diversidade de assuntos tratados. O que pode ser percebido, por exemplo, no ano de 2008, em que o volume de textos é maior, três dos frames encontrados sobrepõem-se. O aumento gradativo no volume dos textos representa o aumento de legitimidade que o assunto adquire no decorrer do tempo, já que o uso de estratégias de sustentabilidade ganha respaldo na aceitação social.

As diversas abordagens encontradas se referem aos discursos que transcendem a análise contextual. As interposições em relação ao contexto também estão ligadas às referências aos atores abordados entre os discursos tratados. Os atores citados pelos textos, em geral, estão relacionados ao trabalho organizacional uma vez que possuem influência relativamente grande em relação às ações desenvolvidas pelas organizações. Assim sendo, percebe-se que o assunto estratégias organizacionais de sustentabilidade não se limita aos muros organizacionais, mas estão conectados às discussões que vêm ocorrendo em toda sociedade e vêm angariando legitimidade (HARDY, 2011).

Seguindo o mesmo caminho, o tipo de organização retratado nos textos, essencialmente indústria de base ou bens do consumo, está relacionado ao grau de relação que possuem com a sociedade, com maior pressão social em torno delas. Observa-se ainda que esse padrão permeia todo o período analisado, não havendo distinção em relação aos frames encontrados.

Além disso, os discursos da mídia são orientados para a explanação dos conceitos que estão sendo formados dentro da sociedade, uma vez que exploram informações capazes de inserir as organizações no contexto dos discursos de sustentabilidade e por conseguinte fazer sentido e constituir a legitimidade.

Assim sendo, as estratégias que emergem do contexto são retratadas pelos meios de comunicação, reforçando o conceito de sustentabilidade. Quando estratégias de sustentabilidade ganham legitimidade, os discursos da mídia possuem uma maior influência sobre a ação organizacional. Esta situação reciprocamente reforçada orienta a ação organizacional no sentido de incentivar estratégias de sustentabilidade. 
Figura 3 - Organizações Citadas nos Textos por Frame

Ecoeficiência

Marketing

Energia e aquecimento global

Responsabilidade social

$0 \%$

$10 \% \quad 20 \% \quad 30 \% \quad 40 \% \quad 50 \%$

$60 \% \quad 70 \% \quad 80 \% \quad 90 \% \quad 100 \%$

1 - Indústria de base

3 - Indústria de bens de consumo

5 - Comércio

9 - Outros tipos de organização
घ 2 - Indústria intermediária

4 - Indústria de ponta

- 6 - Outros serviços

Fonte: elaborado pelos autores com base nos dados da pesquisa.

\subsection{Discussão}

Reflexões inerentes às estratégias organizacionais e a compreensão do seu processo de formação, bem como, os resultados alcançados são assuntos em constante discussão. Aqui, no entanto, propõe-se o entendimento do processo de disseminação de estratégias organizacionais entendendo o papel dos discursos da mídia de negócios como mediadora da ressonância social e aferição de legitimidade que transpassam no contexto institucional.

Modelos de ação por meio dos quais as organizações interagem gerando os mesmos significados organizam a vida social (SCOTT, 2008). Esse processo é percebido não apenas na interação direta das organizações, mas pode se dar por elementos mediadores da ação (FONSECA \& MACHADO-DA-SILVA, 2002). Como pôde ser observado na pesquisa, a mídia de negócios cita, em seus textos, diversos atores presentes no contexto organizacional: organizações, governo, sociedade, funcionários, consumidores, entre outros atores que possuem relação direta com a organização, evidenciando as inter-relações no processo de construção das estratégias organizacionais. 
Assim sendo, dentro de um contexto, as instituições são padrões sociais normativos que, por meio do contexto institucional, servem de parâmetro para a avaliação social que, por sua vez, confere legitimidade às organizações (FONSECA \& MACHADO-DA-SILVA, 2002). A presente pesquisa procurou identificar os padrões de estratégias de sustentabilidade que orientam a ação organizacional no sentido de criar uma instituição que uma vez tida como certa para o meio social, é capaz de gerar legitimidade para a organização que a colocar em prática (MEYER \& ROWAN, 1977; HARDY, 2011). Dessa forma, compreende-se o discurso da mídia como impulsionador da ressonância das estratégias organizacionais, a mesma medida que lhe confere legitimidade por meio da avaliação dada em cada frame.

O entendimento do discurso da mídia com o papel de alastrar conceitos e torná-los socialmente aceitos traz implicações analíticas à medida que se torna um elemento capaz de delinear a compreensão da construção social e estabelecer o grau de propagação das ideias tidas como certas, evidenciando o grau de legitimidade avaliado pelo contexto.

O processo de construção social do conceito de sustentabilidade evidencia-se pelo grau de difusão dos discursos. Ou seja, uma vez que é tratado com maior ênfase na mídia, o assunto ganha destaque não apenas no campo midiático, mas entra em discussão no meio organizacional, o que torna as estratégias de sustentabilidade cada vez mais "tidas como certas", geradoras da legitimidade organizacional (MEYER \& ROWAN, 1977). Isso porque a legitimidade é um compartilhamento congruente de ações dentro de um grupo social (SUCHMAN, 1995).

O grupo social onde as interações ocorrem e as ideias, normas e padrões são socialmente compartilhados é conhecido como contexto institucional (SCOTT, 2008). O contexto, assim, é visto como o local onde as instituições permeiam conduzindo a ação organizacional no sentido de promover ações similares de acordo com as crenças do grupo. Uma vez que o tema sustentabilidade ganha respaldo, organizações tendem a agir em conformidade com o contexto. As organizações, por assim dizer, necessitam da legitimidade dada pelo contexto para perpetuarem sua atuação (MEYER \& ROWAN, 1977).

Nesse sentido, o próprio processo de formação de estratégias organizacionais evidencia o caráter contextual do ambiente em que a 
organização está inserida, bem como, se refere à ação organizacional no sentido de obter vantagens competitivas. A estratégia seria, portanto, a concretização de determinados objetivos por meio de ações táticas, indicando não apenas o grau em que objetivos são atingidos, mas o nível de adequação desses objetivos em relação ao ambiente.

Da mesma forma, segundo Souza Matitz (2009), outras formas de análise levam em conta a construção social, analisando as estratégias retrospectivamente com as consequências das ações. A estratégia estaria relacionada, assim, às direções tomadas pelas organizações em resposta à competição direta e ao contexto. Nesse sentido, o discurso da mídia implica a difusão das estratégias por ele evidenciadas (FAIRCLOUGH, 2001).

A busca pela legitimidade organizacional tem contribuído para a aderência das organizações ao cumprimento de responsabilidades sociais, reforçando estratégias de sustentabilidade. Nesse sentido, verificou-se que emergem do contexto institucional conceitos como responsabilidade social e ambiental corporativa. Dentro de tais conceitos, estudos a respeito dos princípios organizacionais em que a responsabilidade social contribui para a regulamentação governamental fazem parte dos processos de estratégias organizacionais. A análise de como as empresas se relacionam com o ambiente compreende questões sociais de motivação organizacional na área social e relações entre a organização e seus stakeholders. Problemas sociais e ambientais aumentaram a pressão do contexto sobre as estratégias organizacionais (CARVALHO \& KASSAI, 2013).

Os investidores e a sociedade vêm se preocupando cada vez mais com os resultados sociais e ambientais. Tal questão é evidenciada pelo volume e grau de complexidade dos textos publicados na mídia. Quanto mais o conceito de sustentabilidade se desenvolve no meio organizacional, tanto mais o conceito é difundido pela mídia de negócios, o que demonstra que o discurso da mídia traz implicações à realidade organizacional.

Assim sendo, observa-se que a similaridade das estratégias organizacionais em relação às estratégias de sustentabilidade se deve ao fato da difusão de padrões de significados estar cada vez mais evidente nos discursos apresentados pela mídia de negócios. A difusão de significados, da mesma forma, é a própria compreensão de Lawrence e Suddaby (2006) do processo de institucionalização 
que se evidencia no aumento da similaridade das estratégias organizacionais.

Observa-se ainda que as estratégias nem sempre são difundidas diretamente de organização para organização. Isso porque, ações poderiam ser copiadas por concorrentes, fazendo que a organização não apenas não obtivesse ganhos diretos com essa ação, como poderia gerar perda de vantagem competitiva. A mídia, no entanto, intermedeia as ações organizacionais à medida que é capaz de difundir ideias e estratégias que estão sendo desenvolvidas por outras organizações.

Figura 4 - Mídia Difusora das Estratégias

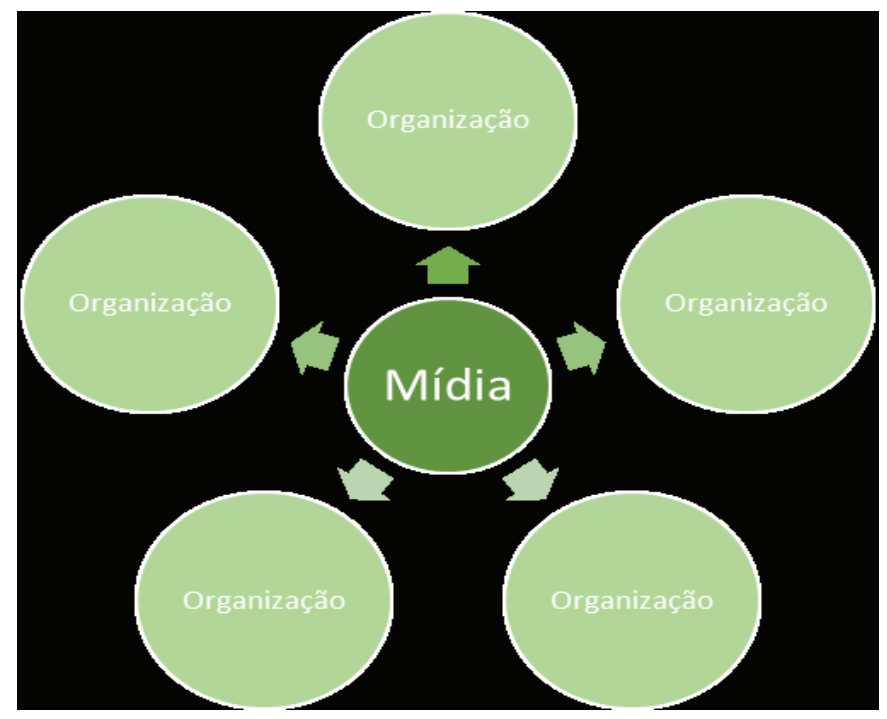

Fonte: elaborado pelos autores com base nos dados da pesquisa.

Como ilustrado na Figura 4, o discurso da mídia é capaz de expressar as ideias que estão no macro discurso, refletindo-se nas ações que são desenvolvidas individualmente pelas organizações. Evidencia-se nos textos analisados na mídia de negócios o alto índice de casos de estratégias de sustentabilidade desenvolvidos pelas organizações. Além das estratégias, os textos apresentam com frequência a necessidade socioambiental que está sendo tratada pelas estratégias propostas, bem como, os resultados sociais, ambientais e econômicos que foram atingidos pelas estratégias de sustentabilidade. 
Se, por um lado, as estratégias não são passadas diretamente entre as organizações, por outro o discurso da mídia é capaz de atingir um grande número de organizações que estão em um mesmo contexto, nivelando o entendimento de estratégias de sustentabilidade entre um grande número de organizações. Zilber (2008) coloca, inclusive, a dinâmica reflexiva que os processos de atribuição de significado das instituições passam. Isso porque, segundo Zilber (2008), a linguagem funciona justamente como elemento mediador do significado atribuído às instituições.

A relação entre as organizações e a mídia apresenta-se como parte do processo de construção social na atribuição de significados. Se, por um lado, para Fairclough (2001) a construção social origina-se na interação dos atores imersos, por outro a interação pode apresentar um elemento mediador capaz de delimitar a atribuição de significados, no caso a mídia de negócios. Assim, a difusão de ideias compartilhadas por meio do discurso implica a atribuição do papel da mídia como mediadora do contexto organizacional.

Se a mídia de negócios é entendida como elemento constitutivo da construção social de instituições, pode-se atribuir aos discursos da mídia o papel de conceitos tidos como certos pelo meio organizacional. Isso porque, observa-se que quanto mais discursos a respeito das estratégias de sustentabilidade, tanto maior é o número de casos de tais estratégias no contexto, o que provoca um aumento também nos discursos da mídia como reflexo da ação social inerente. Essa questão fomenta a seguinte proposição:

Proposição A: O discurso da mídia de negócios é um elemento constitutivo da construção de estratégias organizacionais de sustentabilidade na medida em que promove a difusão de ideias consideradas socialmente aceitas.

Por conseguinte, observa-se que o processo de formação dos discursos de sustentabilidade aqui encontrados reflete não apenas ideias socialmente compartilhadas, mas estratégias organizacionais amplamente difundidas no contexto. Assim, os discursos de sustentabilidade são difundidos de forma dinâmica e reflexiva (ZILBER, 2008). Na realidade, o processo se evidencia na mídia como sustentador da construção social de significados. Segundo Hardy (2011), 
nesse sentido, a difusão de ideias é essencial para a construção, manutenção ou ruptura de padrões sociais. Desse modo, as ideias são difundidas e transformadas de acordo com as modificações que ocorrem no contexto institucional.

Esse conceito, por sua vez, corrobora com as ideias de Phillips et al. (2004). Para os autores, a ação e o discurso são dinâmicos ao longo do tempo e se desenvolvem por meio da construção de textos e instituições. Em processo reflexivo e retroativo, discursos e ações se autossustentam. Ou seja, se por um lado os discursos midiáticos de sustentabilidade sofrem ressonância social, por outro o aumento dos casos de estratégias organizacionais retratados na mídia é um reflexo da continuidade da ação organizacional, e juntos promovem o aumento da legitimidade dentro do contexto institucional.

Figura 5 - Abrangência dos discursos

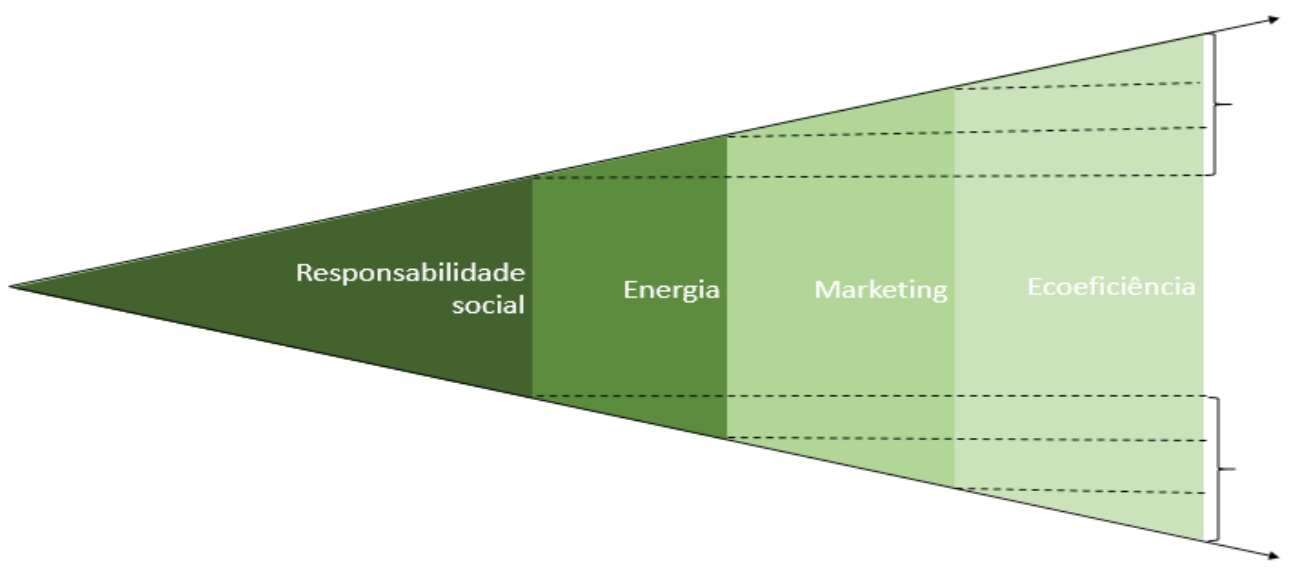

Fonte: elaborado pelos autores com base nos dados da pesquisa.

Seguindo-se o mesmo raciocínio, observa-se que os discursos encontrados na mídia de negócios a respeito das estratégias de sustentabilidade não são concorrentes. Como pode ser observado na Figura 5, os discursos que surgem ao longo do tempo tratam de uma ampliação das estratégias de sustentabilidade, mas os elementos já discutidos não deixam de estar evidentes no discurso.

Isso ocorre porque o próprio conceito de sustentabilidade está em processo de formação. Assim, as ideias vão ganhando escopo e 
profundidade ao longo do tempo em que são exploradas. No caso do conceito de ecoeficiência, por exemplo, a preocupação com a responsabilidade social e ambiental não deixa de estar presente, nem mesmo a utilização de estratégias de ecoeficiência como uma forma de promoção de marketing. No entanto, o conceito de ecoeficiência traz elementos novos como o aproveitamento máximo de recursos.

Ainda assim, as estratégias são entendimentos compartilhados pela construção social promovida pelas interações do contexto. A disseminação dos discursos de sustentabilidade está diretamente ligada à aplicação de tais estratégias (CARRIERI et al., 2009), o que promove a legitimidade de tais ações. Ou seja, macrodiscursos não apenas interferem na ação organizacional como na difusão dos discursos provocada pela mídia. A difusão dos discursos da mídia, por sua vez, promove a disseminação da estratégia no meio organizacional de forma contínua e reflexiva.

Figura 6 - Relação Entre o Discurso da Mídia, as Estratégias e o Contexto
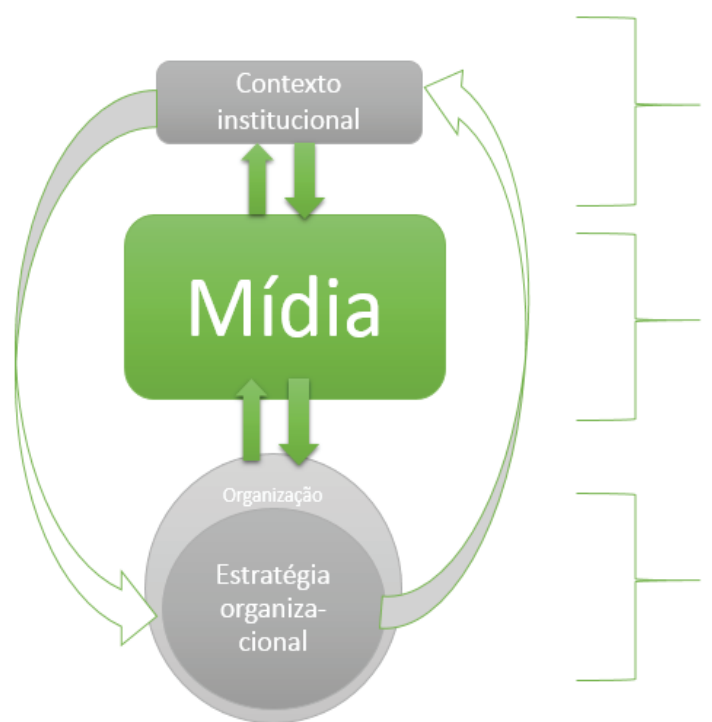

\author{
Macro discursos de
} sustentabilidade

\title{
Discursos da mídia
}

Fonte: elaborado pelos autores com base nos dados da pesquisa.

O que pode ser entendido por meio da Figura 6 trata da inserção da mídia como um elemento mediador no processo reflexivo de construção social capaz de atribuir significados, nivelar enten- 
dimentos e orientar as estratégias organizacionais. Sendo assim, é possível elaborar a seguinte proposição:

Proposição B: A mídia, enquanto elemento institucional que expressa ressonância social, é mediadora da relação entre o contexto institucional e a agência organizacional.

Proposição B1: A mídia é um elemento que transpassa o contexto institucional funcionando como amplificadora dos conceitos socialmente aceitos que permeiam o contexto.

Ainda que a mídia não seja capaz de refletir o contexto institucional em sua integralidade, nem mesmo possua controle sobre a ação das organizações, tem um papel mediador no entendimento compartilhado de instruções sociais. Isso porque a mídia é constituinte do sistema e funciona como intermediária das relações sociais. Como o discurso da mídia atinge um grande número de organizações inseridas no mesmo contexto, elas são capazes de equiparar as ideias aceitas no meio difundindo os conceitos compartilhados.

Proposição B2: O discurso da mídia representa uma face do contexto institucional e confere legitimidade às ações organizacionais.

Da mesma forma, o discurso midiático reflete as ideias compartilhadas, aumentando a legitimidade das ações. Como as instituições que permeiam o contexto são repassadas às organizações por meio da mídia, a mídia torna-se elemento que amplia a legitimidade das estratégias abordadas, promovendo ainda mais a aplicação de tais ações.

\section{CONSIDERAÇões FINAIS}

Destaca-se que a presente pesquisa procurou entender a construção do conceito de estratégias de sustentabilidade por meio da análise do discurso da mídia que promove a ressonância social e aumento da legitimidade das estratégias, não obstante, sabe-se que a institucionalização efetiva de práticas sociais só é reconhecida quando tratada em nível de gerações (GIDDENS, 1984). Apesar disso, já se observa uma ideia reforçada mutuamente pelo discurso 
da mídia e as práticas organizacionais, apresentando evidências do processo de institucionalização.

Observa-se também que os textos encontrados possuem uma evolução tanto no volume das discussões como na própria profundidade em que o assunto é tratado. Em síntese, na medida em que o entendimento da sustentabilidade muda, os discursos são alterados, tornam-se mais abrangentes e profundos. Nesse sentido, a mídia é um elemento capaz de intervir na prática social do contexto institucional, bem como, da realidade organizacional. Assim sendo, não apenas o contexto e as organizações se interferem mutuamente como também estão sob domínio dos discursos da mídia, tanto refletindo em seus discursos como sendo alvo de influência. Dessa maneira, a mídia que expressa ressonância também se insere no papel de ator que contribui com a construção dos conceitos sociais.

Apesar disso, algumas limitações restringiram um entendimento mais holístico da questão na presente pesquisa. Primeiramente pode-se dizer que uma análise que utilizasse um número maior de veículos de comunicação traria mais validade para os dados e observações levantadas. Além disso, a condição temporal de apenas 20 anos é muito reduzida para que possamos compreender um processo de institucionalização completo de um conceito. Ademais, outras bases e fontes de dados poderiam ter sido consultadas a fim de confrontar informações do contexto, bem como, a aplicação das estratégias de sustentabilidade desenvolvidas pelas organizações.

A discussão acadêmica inerente, afinal, não está apenas na explanação da construção social do conceito de sustentabilidade aplicado nas organizações, mas na mídia como elemento legitimador fundamental no processo de institucionalização das práticas organizacionais socialmente aceitas.

\section{REFERÊNCIAS}

ALIGLERI, L., ALIGLERI, L. A., \& KRUGLIANSKAS, I. (2009). Gestão socioambiental: responsabilidade e sustentabilidade do negócio. São Paulo: Atlas.

BARBIERI, J. C. (2007). Gestão ambiental empresarial: conceitos, modelos e instrumentos, 2. ed. São Paulo: Saraiva.

BERGER, P. L., \& LUCKMANN, T. (1998). Construção social da realidade, 29. ed. Petrópolis: Vozes.

BOXENBAUM, E., \& JONSSON, S. (2008). Isomorphism, diffusion and decoupling. In: 
GREENWOOD, R.; OLIVER, C.; SAHLIN, K.; SUDDABY, R. (Orgs.). The Sage Handbook Of Organizational Institutionalism, 78-98.

CARRIERI, A. D. P., LEITE DA SILVA, A. R., \& PIMENTEL, T. D. (2009). O Tema da Proteção Ambiental Incorporado nos Discursos da Responsabilidade Social Corporativa. Revista de Administração Contemporânea, 13(1).

CARVALHO, L. N., \& KASSAI, J. R. (2013). Relato Integrado. In: FONTES FILHO, J. R.; LEAL, R. P. C. O Futuro Da Governança Corporativa: Desafios E Novas Fronteiras. São Paulo: Saint Paul.

CAVAZOS, D. E., \& RUTHERFORD, M. A. (2011). Examining how media coverage impacts the regulatory notice and comment process. The American Review of Public Administration, 41(6), 625-638. doi: 10.1177/0275074010387660.

CHIGONA, W., \& MOOKETSI, B. (2011). In the Eyes of the Media: Discourse of an ICT4D Project in a Developing Country. Electronic Journal on Information Systems in Developing Countries, 46, 1-16. Retrieved from http://144.214.55.140/ojs2/index.php/ejisdc/index.

COELHO, A. L. D. A., \& GODOI, C. K. (2010). Coerência entre o discurso institucional e o discurso midiático sobre a sustentabilidade. Revista de Gestão Social e Ambiental, 4(3). doi: 10.5773/rgsa.v4i3.329.

CZARKNIAWSKA, B., \& JOERGES B. (1996). The Travel Of Ideas. In: CZARNIAWSKA, B.; SEVON, G. (Orgs.). Translating Organizational Change. Berlin: de Gruyter.

DEEPHOUSE, D. L. (1999). To be different, or to be the same? It's a question (and theory) of strategic balance. Strategic management journal, 20(2), 147-166.

DIRIKX, A., \& GELDERS, D. (2010). To frame is to explain: A deductive frame-analysis of Dutch and French climate change coverage during the annual UN Conferences of the Parties. Public Understanding of Science, 19 (6), 732-742. doi: 10.1177/0963662509352044.

FAIRCLOUGH, N. (2001). Discurso e mudança social. Brasília: UnB.

FONSECA, V. S. D., \& MACHADO-DA-SILVA, C. L. (2002). Conversação entre abordagens da estratégia em organizações: escolha estratégica, cognição e instituição. Organizações \& Sociedade, 9 (25), 93-109. doi: 10.1590/S1984-92302002000300006.

GIDDENS, A. (1984). Sociologia: Questões E Problemas. In: Giddens, A. (Org.). Sociologia: Uma Breve, Porém Introdução. Rio De Janeiro: Zahar.

GOLSORKHI, D., ROULEAU, L., SEIDL, D., \& VAARA, E. (2010). Cambridge Handbook Of Strategy As Practice. New York: Cambridge Univ. Press.

GREENWOOD, R., OLIVER, C., SAHLIN, K., \& SUDDABY, R. (2008). Introduction. In: GREENWOOD, R., OLIVER, C., SAHLIN, K., \& SUDDABY, R. (Orgs.). The Sage Handbook Of Organizational Institutionalism. Los Angeles: Sage, 1-46.

GUIMARÃES, R., \& FONTOURA, Y. (2012). Desenvolvimento sustentável na Rio+20: discursos, avanços, retrocessos e novas perspectivas. Cadernos Ebape. BR, 10(3), 508-532. Recuperado de http://bibliotecadigital.fgv.br/ojs/index.php/cgpc/index.

HARDY, C. (2011). How institutions communicate; or how does communicating institutionalize?. Management Communication Quarterly, 25 (1), 191-199. doi: 10.1177/0893318910389295.

LAMMERS, J. C. (2011). How institutions communicate: Institutional messages, institutional logics, and organizational communication. Management Communication Quarterly, 25 (1), 154-182. doi: 10.1177/0893318910389280. 
LAWRENCE, T.; SUDDABY, R. (2006). Institutions And Institutional Work. In: S. R. CLEGG, C. HARDY, T. B. LAWRENCE, \& W. R. NORD (Orgs.). Handbook Of Organization Studies. London: Sage.

OLIVEIRA, P. D. M. N. (2012). Entre a "Guerra" e a "Paz": Os Modelos de Policiamento e o Discurso Midiático Sobre Segurança Pública no Rio De Janeiro. Cadernos Gestão Pública e Cidadania, 17 (61).

OLIVEIRA, S. A. Adamouglu de., GODRI, L., COSTA, M. C., \& GUARIDO FILHO, E. R. (2016). Análise do Discurso e seu uso nos Estudos Organizacionais: Estudo dos Contextos de Citação de Phillips, Lawrence e Hardy. Revista Eletrônica de Ciência Administrativa, 15 (1), 40. doi: 10.21529/RECADM.2016004.

PHILLIPS, N., LAWRENCE, T. B., \& HARDY, C. (2004). Discourse and institutions. Academy of management review, 29(4), 635-652. Retrieved from http://aom.org/.

RIAZ, S., BUCHANAN, S., \& BAPUJI, H. (2011). Institutional Work Amidst The Financial Crisis: Emerging Positions Of Elite Actors. Organization, 18(2), 187-214. doi: $10.1177 / 1350508410389630$.

RICHARDSON, J. (2007). Analyzing Newspaper: An Approach From Critical Discourse Analysis. Palgrave Macmillan.

RIVENBURGH, N. K. (2013). Media framing of complex issues: The case of endangered languages. Public Understanding of Science, 22 (6), 704-717. doi: 10.1177/0963662511426033.

SAHLIN, K., \& WEDLIN, L. (2008). Circulating Ideas: Imitations, Translations And Editing. In: GREENWOOD, R.; OLIVER, C.; SAHLIN, K.; SUDDABY, R. (Orgs.). The Sage Handbook Of Organizational Institutionalism. Los Angeles: Sage.

SCOTT, W. R. (2003). Institutional Carriers: Reviewing Modes Of Transporting Ideas Over Time And Space And Considering Their Consequences. Industrial And Corporate Change, 12(4), 879-894. doi: 10.1093/icc/12.4.879.

SCOTT, W. R. (2008). Institutions And Organizations: Ideas And Interests (3. ed.). Thousand Oaks: Sage.

SOUZA MATITZ, Q. R. Aspectos Semânticos, Formais E Funcionais Do Conceito Desempenho Em Estudos Organizacionais E Estratégia: Um Modelo Analítico. Doutorado em Administração, Universidade Federal do Paraná, Curitiba, PR, Brasil.

SUCHMAN, M. C. (1995). Managing legitimacy: Strategic and institutional approaches. Academy of management review, 20 (3), 571-610. Retrieved from http://aom.org/.

ZILBER, T.; B. I. (2008). The Work Of Meaning In Institutional Process And Thinking. In: GREENWOOD, R.; OLIVER, C.; SAHLIN, K.; SUDDABY, R. (Orgs.). The Sage Handbook Of Organizational Institutionalism. Los Angeles: Sage, 151-169.

Recebido em: 5-5-2017

Aprovado em: 10-10-2017

Avaliado pelo sistema double blind review.

Editor: Coordenação do PPGA/UMESP

Disponível em http://mjs.metodista.br/index.php/roc 